\title{
Economic burden and psycho-social implications of Non- Communicable Diseases on adults and their households in South-west Nigeria
}

\author{
Akintunde TS1, Adeomi AA ${ }^{2}$, Akintunde AA ${ }^{* 3,4}$ \\ 1Department of Economics, Osun State University, Okuku Campus, Okuku, Osun State, Nigeria \\ 2Department of Community Health, Obafemi Awolowo University, Ile-Ife, Osun State, Nigeria \\ ${ }^{3}$ Department of Medicine, Ladoke Akintola University of Technology, Ogbomoso, Oyo State, Nigeria \\ ${ }^{4}$ Department of Medicine, Bowen University/Bowen University Teaching Hospital, Ogbomoso, Oyo State, \\ Nigeria
}

\author{
*Correspondence: Dr. AA Akintunde, P.O Box 3238, Osogbo, Osun State, Nigeria; Email: \\ aakintunde@lautech.edu.ng; ORCID - http://orcid.org/0000-0002-1188-6041.
}

\begin{abstract}
Background: Non-communicable diseases (NCDs), are associated with significant economic and psycho-social burden on sufferers.

Objective: To compare the economic burden of disease management on adults with NCDs and control subjects in Ogbomoso, Nigeria.

Method: A total of 322 participants consisting of 165 adults with at least one of two NCDs - hypertension and diabetes mellitus- and 157 controls (without NCDs) were recruited by stratified random sampling method. The participants were evaluated for the economic burden and psycho-social implications of NCDs on them and on their households.

Results: The presence of NCDs was associated with significantly higher psycho-social implication on the subjects including poorer patient-reported personal health assessment, higher frequency of hospital visits and longer average total hours of hospital visits compared to the controls. A significant proportion of subjects with NCDs depended on family supports for their hospital bills $(32.7 \%$ vs. $7.6 \%)$. The total average monthly health expenditure among subjects with NCDs was significantly higher. Catastrophic health expenditure was found in $12.1 \%$ of subjects with NCDs who indicated their hospital bills were far higher than their total monthly wages.

Conclusion: The management of NCDs is associated with significantly higher psycho-social and economic impact on affected individuals. There is a need for appropriate health insurance scheme and health system financing programs to reduce economic and psycho-social burdens, minimise long-term complications and improve quality of life.
\end{abstract}

Keywords: Economic burden, Non-communicable diseases, Out-of-pocket spending, Psycho-social implications, Nigeria.

\section{Introduction}

Non-communicable diseases (NCDs) pose serious threats to economic growth and development of the society or nation. ${ }^{[1]}$ NCDs may be described as diseases of long duration, generally slow progression and which are the major causes of adult mortality and morbidity worldwide. [2] NCDs generally include cardiovascular diseases (including heart 
diseases and stroke), diabetes mellitus, cancers and chronic respiratory diseases (including chronic obstructive pulmonary disease and asthma). ${ }^{[2,3]}$ About 5 million Nigerians were projected to have died of NCDs by the year 2015 with diabetes mellitus alone projected to have caused about $52 \%$ of the total mortality. [3] Keening et al. opined that the impact of NCDs in Nigeria is enormous and glaring, [4] and mostly caused by poor diet, physical inactivity, tobacco and alcohol use. [5]

NCDs account for a large proportion of morbidity and mortality in low- and middleincome countries. [6] The financial cost of NCDs may be both direct and indirect. Direct costs include those incurred in health care consultations, drugs and medicaments, laboratory services and hospitalization. It also includes other costs that are related to seeking health care such as transportation and special regimen among others. Indirect costs include those that are related to loss of working time and income for the patient and the caregiver for the period of medical consultation, hospitalization and rehabilitation. [7, 8] The impact of NCDs is expected to be different between the high-income countries and lowand middle-income countries (LMICs) such as Nigeria. This is mainly because of the modes of health system financing and management variability between the two settings. While a majority of subjects in developed countries rely on health insurance schemes for health financing, the proportion and scope of coverage of health insurance schemes for NCDs in LMICs is severely limited. [9]

The overall prevalence of NCDs in many studies is reportedly high in Nigeria with up to $32.8 \%$ reported from south-south Nigeria. ${ }^{[4]}$ As NCDs become increasingly burdensome, there is associated expected the psycho-social and economic impact on sufferers with an additive effect on the morbidity and mortality pattern. ${ }^{[4,5]}$ The economic cost of NCDs in Nigeria in the year 2005 was estimated at about 400 million US Dollars and it had risen to about 8 billion US Dollars by 2015. [2, 6] NCDs represent a high cost to society and contribute to social inequalities. $\left.{ }^{8}, 9\right]$ This implies a large and growing burden to individuals, families, and the public and private sectors. The burden of NCDs on health systems, economies, educational systems, and taxpayers can be great. ${ }^{[9,10]}$ There is a problem of high-income inequality in Nigeria and if proper measures are taken, millions of premature deaths could be prevented while avoiding lost productivity and financial hardship to families occasioned by rising burden of NCDs. ${ }^{[1]}$ Some NCDs are linked to urbanization, modernization, affluence and changing lifestyles in developing countries. [12,13] Sedentary occupation and consumption of a wider diversity of local and foreign foods rich in high complex fats have also contributed to the incidence of these diseases. [14] Unfortunately, the reduction of public spending on health care and the introduction of user fees has created problems of inaccessibility and inequity in healthcare in most developing countries, particularly Nigeria. [15] Health services in Africa are typically under-resourced, underfunded with the available resources dedicated primarily to communicable diseases. NCDs remain largely unrecognised as significant health problems by most African health management authorities hence, the direct effects are not accounted for. $[14,15]$

The objective of this study was to explore the economic and financial impacts and psychosocial implications among individuals with NCDs and their households in South-west Nigeria.

\section{Methods}

This study was a cross-sectional study carried out between June and December 2017. The study sites included the Cardiology Clinics of three specialist clinics: Ladoke Akintola University of Technology Teaching Hospital, Ogbomoso, Bowen University Teaching 
Hospital, Ogbomoso, both in Oyo State and Goshen Heart Clinic, Osogbo, Osun State, all in South-west Nigeria. Subjects were included if they had a diagnosis of Non-communicable Disease- specifically, hypertension, diabetes or both. Subjects with mental disorders and those whose life expectancy was likely less than a year were excluded. The participants included 165 subjects attending any of these facilities for the management of either or both of hypertension and diabetes mellitus and had attended the clinic for at least one year. One hundred and fifty-seven age- and sex-matched controls without any NCDs were also recruited from the community: including churches, mosques and among hospital staff.

A semi-structured validated questionnaire was given to participants to fill and they were encouraged to be as open as possible as they were assisted by research assistants when necessary. Some of the information obtained from the questionnaire included the gender of the participants, age range, educational status, religion, average monthly income of the participants, average total household income, number of people in the household who were employed, self-perception of participants' health status, frequency of hospital visits, history of previous medical admission, hospital payment plan, range of average monthly hospital payment and mode of transportation to the hospital. Catastrophic Health Expenditure referred to the situation when average total hospital bill exceeded average total income.

The responses were collated and analysed. Statistical analysis was done with the aid of the Statistical Package for Service Solution (IBM SPSS Version 23, Chicago Ill. USA). Quantitative data were summarized as means and standard deviations while qualitative data were summarized as frequencies and proportions. Chi-Square test was used to compare the difference between the proportions of categorical variables with
Fisher's exact test or Yate's correction performed as appropriate.

\section{Ethical considerations}

Ethical approval was obtained from the Institutional Research Board of Ladoke Akintola University of Technology Teaching Hospital, Ogbomoso, Oyo State, Nigeria. Informed consent was obtained from all the participants.

\section{Results}

One hundred and sixty-five subjects with hypertension and/or diabetes mellitus and 1157 age- and sex-matched controls were recruited into the study. The $>60$ years age group was the most frequent in both groups and this was followed closely by those in the 51-60 years age category. The males comprised $87(52.7 \%)$ of the subjects and 88 (56.1\%) of the controls. Majority of study participants were self-employed and retirees, mainly in the low socio-economic class when their average monthly income was taken into consideration. This suggests limited resources for selfsustenance and health financing. About half of the study participants and the control group had tertiary education. The average monthly income of study participants are as shown in Table I. Forty-one $(24.8 \%), 46(27.9 \%)$ and $26(15.8 \%)$ received an average of $<10,000$ Naira (equivalent to 31 US Dollar a month) among study participants compared to $25(15.9 \%), \quad 34(21.7 \%) \quad$ and $32(20.4 \%)$ respectively among control subjects. Only $41(24.8 \%)$ of subjects with NCDs had a total average household income more than 150,000 Naira (equivalent to about 420 US Dollars) compared to $36(22.9 \%)$ of the control subjects $(p=0.116)$ as shown in Table I.

The psycho-social implications of the treatment of NCDs are shown in Table II. A significant proportion of subjects with NCDs described their personal health compared to others as either worse or much worse (7.9\%) 
while none of the control participants gave a similar comparison and this difference was statistically significant. Similarly, 14 (8.5\%) of study participants opined that at least one other family member has had a prolonged /chronic illness before or at present compared to none among controls, $\mathrm{p}=0.0000$. The frequency of reported NCDs in the families was not significantly different between the two groups.

Table I: Socio-demographic Characteristics of Respondents with NCDs and Controls

\begin{tabular}{|c|c|c|c|}
\hline \multirow{2}{*}{$\begin{array}{l}\text { Variables } \\
(n=322)\end{array}$} & \multicolumn{2}{|l|}{ NCD status (\%) } & \multirow[t]{2}{*}{ Statistics } \\
\hline & Present $(n=165)$ & Absent $(n=157)$ & \\
\hline \multicolumn{4}{|l|}{ Age groups (in years) } \\
\hline $21-20$ & $6(3.6)$ & $8(5.1)$ & \multirow{5}{*}{$\begin{array}{l}X^{2}=8.739 \\
d f=4 \\
p=0.068\end{array}$} \\
\hline $31-40$ & 19 (11.5) & $24(15.3)$ & \\
\hline $41-50$ & $13(7.9)$ & $26(16.6)$ & \\
\hline $51-60$ & $42(25.5)$ & $36(22.9)$ & \\
\hline$>60$ & $85(51.5)$ & $63(40.1)$ & \\
\hline \multicolumn{3}{|l|}{ Gender } & \multirow{3}{*}{$\begin{array}{l}x^{2}=0.358 \\
\text { do }=1 \\
p=0.550\end{array}$} \\
\hline Male & $87(52.7)$ & $88(56.1)$ & \\
\hline Female & $78(47.3)$ & $69(43.9)$ & \\
\hline \multicolumn{4}{|l|}{ Occupation } \\
\hline Civil servant & $36(21.8)$ & $28(17.8)$ & \multirow{8}{*}{$\begin{array}{l}\chi^{2}=12.755 \\
d f=7 \\
p=0.078\end{array}$} \\
\hline Private worker & $22(13.3)$ & $28(17.8)$ & \\
\hline Self-employed & $42(25.5)$ & $36(22.9)$ & \\
\hline Retiree & $37(22.4)$ & $26(16.6)$ & \\
\hline Unemployed & $9(5.5)$ & $10(6.4)$ & \\
\hline Others & $8(4.8)$ & $4(2.5)$ & \\
\hline Trader & $8(4.8)$ & $23(14.6)$ & \\
\hline Farmer & $3(1.8)$ & $2(1.3)$ & \\
\hline \multicolumn{3}{|l|}{ Religion } & \multirow{3}{*}{$\begin{array}{l}x^{2}=0.334 \\
d f=1 \\
p=0.563\end{array}$} \\
\hline Christianity & $105(63.6)$ & $95(60.5)$ & \\
\hline Islam & $60(36.4)$ & $62(39.5)$ & \\
\hline \multicolumn{4}{|l|}{ Educational Status } \\
\hline No formal education & $32(19.4)$ & $29(18.5)$ & \multirow{4}{*}{$\begin{array}{l}\chi^{2}=3.761 \\
d f=3 \\
p=0.288\end{array}$} \\
\hline Primary school & $12(7.3)$ & $14(8.9)$ & \\
\hline Secondary school & $36(21.8)$ & $22(14.0)$ & \\
\hline Tertiary school & 85 (51.5) & $92(58.6)$ & \\
\hline \multicolumn{4}{|c|}{ Monthly income (in naira) } \\
\hline$<10,000$ & $41(24.8)$ & $25(15.9)$ & \multirow{6}{*}{$\begin{array}{l}\chi^{2}=10.411 \\
d f=5 \\
p=0.064\end{array}$} \\
\hline $10,000-39,000$ & $46(27.9)$ & $34(21.7)$ & \\
\hline $40,000-69,000$ & $26(15.8)$ & $32(20.4)$ & \\
\hline $70,000-99,000$ & $21(12.7)$ & $26(16.6)$ & \\
\hline $100,000-149,000$ & $20(12.1)$ & $18(11.5)$ & \\
\hline$\geq 150,000$ & $11(6.7)$ & $22(14.0)$ & \\
\hline \multicolumn{4}{|c|}{ Total Household Income (in naira) } \\
\hline$<10,000$ & & & \multirow{7}{*}{$\begin{array}{l}\chi^{2}=8.836 \\
d f=5 \\
p=0.116\end{array}$} \\
\hline $10,000-39,000$ & $17(10.3)$ & $27(17.2)$ & \\
\hline $40,000-69,000$ & $31(18.8)$ & $24(15.3)$ & \\
\hline $70,000-99,000$ & $31(18.8)$ & $26(16.6)$ & \\
\hline $100,000-149,000$ & $20(12.1)$ & $30(19.1)$ & \\
\hline \multirow[t]{2}{*}{$\geq 150,000$} & $25(15.2)$ & $14(8.9)$ & \\
\hline & $41(24.8)$ & $36(22.9)$ & \\
\hline
\end{tabular}


Table II: Psycho-Social implications of Non-Communicable Disease Management

\begin{tabular}{|c|c|c|c|}
\hline \multirow{2}{*}{$\begin{array}{l}\text { Variables } \\
(n=322)\end{array}$} & \multicolumn{2}{|c|}{ NCD status (\%) } & \multirow[t]{2}{*}{ Statistics } \\
\hline & $\begin{array}{l}\text { Present } \\
(n=165)\end{array}$ & $\begin{array}{l}\text { Absent } \\
(\mathrm{n}=157)\end{array}$ & \\
\hline \multicolumn{4}{|l|}{ Description of own Health Status } \\
\hline Good & $44(26.7)$ & $30(19.1)$ & $\chi^{2}=22.321$ \\
\hline Better & $59(35.8)$ & $88(56.1)$ & $\mathrm{df}=4$ \\
\hline No change & 49 (29.7) & $39(24.8)$ & ${ }^{*} \mathrm{p}<0.001$ \\
\hline Bad & $11(6.7)$ & $0(0.0)$ & \\
\hline Worse & $2(1.2)$ & $0(0.0)$ & \\
\hline \multicolumn{4}{|l|}{ Family member often falls sick } \\
\hline Yes & $12(7.3)$ & $12(7.6)$ & $\chi^{2}=4.835$ \\
\hline No & $148(89.7)$ & $145(92.4)$ & $\mathrm{df}=2$ \\
\hline Yes, but much better now & $5(3.0)$ & $0(0.0)$ & $\mathrm{p}=0.089$ \\
\hline \multicolumn{4}{|l|}{ Family member has prolonged illness } \\
\hline Yes & $14(8.5)$ & $0(0.0)$ & $X^{2}=35.229$ \\
\hline No & 145 (87.9) & $123(78.3)$ & $\mathrm{df}=2$ \\
\hline Not sure & $6(3.6)$ & $34(21.7)$ & ${ }^{*} \mathrm{p}<0.0001$ \\
\hline \multicolumn{4}{|l|}{ NCD is common in your family } \\
\hline Yes & $49(29.7)$ & $4(2.5)$ & $X^{2}=0.334$ \\
\hline No & $91(55.2)$ & $117(74.5)$ & $\mathrm{df}=1$ \\
\hline Not sure & $25(15.1)$ & $36(22.9)$ & $\mathrm{p}=0.563$ \\
\hline \multicolumn{4}{|l|}{ NCD common in your environment } \\
\hline Yes & $67(40.6)$ & $27(17.2)$ & $X^{2}=21.740$ \\
\hline No & $44(26.7)$ & $64(40.8)$ & $\mathrm{df}=2$ \\
\hline Not sure & $54(32.7)$ & $66(42.0)$ & ${ }^{*} \mathrm{p}<0.001$ \\
\hline \multicolumn{4}{|l|}{ Number of Hospital visits in a month } \\
\hline Once & $149(90.3)$ & $149(94.9)$ & $\chi^{2}=6.027$ \\
\hline Twice & $14(8.5)$ & $4(2.5)$ & $\mathrm{df}=2$ \\
\hline Thrice & $2(1.2)$ & $4(2.5)$ & ${ }^{*} \mathrm{p}=0.049$ \\
\hline \multicolumn{4}{|c|}{ Number of hours spent during hospital visits } \\
\hline \multicolumn{4}{|c|}{$<1$ hour } \\
\hline $1-2$ hours & $20(12.1)$ & $28(17.8)$ & $X^{2}=16.549$ \\
\hline $3-4$ hours & $35(21.2)$ & $20(12.7)$ & $\mathrm{df}=3$ \\
\hline \multirow[t]{2}{*}{$5-6$ hours } & $87(52.7)$ & $103(65.6)$ & ${ }^{*} \mathrm{p}=0.001$ \\
\hline & $23(13.9)$ & $6(3.8)$ & \\
\hline Past history of hospital admission & & & $\chi^{2}=53.486$ \\
\hline Yes & $95(57.6)$ & $30(19.1)$ & $\mathrm{df}=2$ \\
\hline No & $70(42.4)$ & $127(80.9)$ & ${ }^{*} \mathrm{p}<0.0001$ \\
\hline
\end{tabular}

* Statistically significant

However, more people among those with NCDs were aware of the high prevalence of NCDs in their environment compared to controls (40.6\% vs.17.2\%, p = 0.000) (Table II). The subjects with NCDs were likely to visit the hospital more frequently compared to controls. Sixteen $(9.7 \%)$ subjects visited the hospital at least twice monthly compared to 8 $(5.0 \%, p=0.049)$ among controls. The proportion of subjects with NCDs who spent at least five hours during each hospital visit was significantly higher compared to controls (13.9\% vs. $3.8 \%$ respectively, $p=0.0001$ (Table II). Majority of those with NCDs reported a previous history of medical or surgical admission compared to controls and this was also statistically significant $(57.6 \%$ vs $19.1 \%$ respectively, $p=0.0000$ as shown in Table II. 
The economic burden and implications of management of NCDs among study participants are shown in Table III. The commonest mode of payment in the study population was out-of-pocket with a significant proportion of the subjects being dependent on family support for their healthcare financing $(32.7 \%$ vs. $7.6 \%, \mathrm{p}=$ 0.0000 ). Only $1.2 \%$ of subjects with NCDs were on any form of health insurance for the payment of their medical bills. All these differences achieved statistical significance. The total average personal monthly spending was significantly different between the two groups. More than one-third (38.2\%) of study subjects with NCDs spent on average greater than 10,000 Naira compared to only $3.8 \%$ in the control group. Among subjects with NCDs, $3.0 \%$ and $1.2 \%$ spent between 100,000 150,000 Naira (278-417 US Dollars) and more than 150,000 Naira (417 U.S Dollars) respectively compared to none among controls (Table III).

Comparatively, when the average monthly healthcare spending was related to average monthly income, a serious case of impoverishing was noticed among subjects with NCDs; 38 (23.0\%) had average total hospital bill in a similar range with income compared to $27(17.2 \%)$ among the controls. Twenty (12.1\%) subjects with NCDs had catastrophic health expenditure.

Table III: Economic burden of Disease Management

\begin{tabular}{|c|c|c|c|}
\hline \multirow{2}{*}{$\begin{array}{l}\text { Variables } \\
(\mathrm{n}=322)\end{array}$} & \multicolumn{2}{|c|}{ NCD status (\%) } & \multirow[t]{2}{*}{ Statistics } \\
\hline & $\begin{array}{l}\text { Present } \\
(n=165)\end{array}$ & $\begin{array}{l}\text { Absent } \\
(\mathrm{n}=157)\end{array}$ & \\
\hline \multicolumn{4}{|l|}{ Mode of payment for medical treatment } \\
\hline Out of pocket & & & $\chi^{2}=36.013$ \\
\hline Health Insurance & $108(65.5)$ & $139(88.5)$ & $\mathrm{df}=3$ \\
\hline Family support & $2(1.2)$ & $0(0.0)$ & ${ }^{*} \mathrm{p}<0.001$ \\
\hline \multirow[t]{2}{*}{ Others } & $54(32.7)$ & $12(7.6)$ & \\
\hline & $1(0.6)$ & $6(3.8)$ & \\
\hline \multicolumn{4}{|l|}{ Mode of transportation to hospital } \\
\hline Car & $94(57.0)$ & $82(52.2)$ & $\chi^{2}=6.778$ \\
\hline Motorcycle & $66(40.0)$ & $59(37.6)$ & $\mathrm{df}=2$ \\
\hline Trekking & $5(3.0)$ & $16(10.2)$ & ${ }^{*} \mathrm{p}=0.034$ \\
\hline \multicolumn{4}{|c|}{$\begin{array}{l}\text { Amount spent on hospital bills monthly (in } \\
\text { naira) }\end{array}$} \\
\hline$<10,000$ & $102(61.8)$ & $151(96.2)$ & $\chi^{2}=57.150$ \\
\hline $10,000-39,000$ & $45(27.3)$ & $6(3.8)$ & $\mathrm{df}=5$ \\
\hline $40,000-69,000$ & $9(5.5)$ & $0(0.0)$ & ${ }^{*} \mathrm{p}<0.0001$ \\
\hline $70,000-99,000$ & $2(1.2)$ & $0(0.0)$ & \\
\hline $100,000-149,000$ & $5(3.0)$ & $0(0.0)$ & \\
\hline$\geq 150,000$ & $2(1.2)$ & $0(0.0)$ & \\
\hline \multicolumn{4}{|c|}{$\begin{array}{l}\text { Relationship between monthly income and } \\
\text { hospital bills }\end{array}$} \\
\hline Hospital bill less than income & $107(64.8)$ & $130(82.8)$ & $\chi^{2}=23.920$ \\
\hline Hospital bill same range with income & $38(23.0)$ & $27(17.2)$ & $\mathrm{df}=2$ \\
\hline Hospital bill more than income & $20(12.12)$ & $0(0.0)$ & ${ }^{*} \mathrm{p}<0.001$ \\
\hline
\end{tabular}

* Statistically significant 


\section{Discussion}

Diseases deprive individuals of their health and productive potential. The burden of chronic diseases may invariably challenge an individual or household income and savings and compete with investment activities. At the national level, chronic diseases reduce life expectancy and ultimately economic productivity, thus depleting the quality and quantity of countries' labour force. This may eventually lead to reduced national income. [16]

According to Engelgau, Karan and Mahal, health care delivery to reduce the incidence of NCDs is very challenging in developing countries. [17] Even when such care is available, individuals with NCDs will continue to face significant risks of hospitalization and the associated costs of financing care. Ekpenyong et al. in the year 2012, showed the double burden of non-communicable diseases and their risk factors in sub-Saharan Africa particularly in Nigeria. ${ }^{[4]}$ It also represents a major threat to fragile health systems and emphasises the need for innovative integrative approaches to health care delivery. $[4,18]$

Several studies have been done among developed nations on the economic burden of NCDs. ${ }^{[19-21]}$ As a result of wealth inequality and other factors including poor health system, poor health financing, high fertility rate and increasing poverty, the burden of NCDs in LMICs appears very different and marked as suggested by the findings in this study. This study revealed that the economic burden of NCDs among its sufferers is unacceptably high with a very high risk of plunging them into poverty and deprivation. Many NCDs provide significant reward from primary and secondary prevention. From the public health perspective, it will be financially rewarding if appropriate interventions are implemented to halt the rapid epidemiologic transition with the rising prevalence of NCDs
This is similar to reports from other African nations. [22-24] An earlier study reported some heterogeneity in wealth and gender status as it relates to health care spending and quality of health care obtained among rural dwellers in Kwara State, Nigeria. [25] It was also noted that the expenditures of the poor households represent a higher share of their annual household income/consumption as observed in this study where a higher proportion of subjects had their average monthly health spending almost equivalent to their monthly income. Sadly, about $12 \%$ even had income less than their average monthly health care spending. This study also revealed that NCDs can impose significant economic and large health cost on affected individuals and can further plunge poor people down the line of poverty. [26] It also revealed a dismally low level of insurance cover for healthcare expenditure in South-west Nigeria. Out-ofpocket health expenditure becomes limited in many terms: desired health care may not be readily available and disease severity would have been advanced before these expenses are met. The 2016 Global Burden of Diseases similarly reported that out-of-pocket expenses were responsible for the majority of health care expenditure in Nigeria, which was estimated to be about 28.1 Billion US Dollars. [27] It is increasingly being recognized that NCDs are important international and developmental issue globally with a potential to undermine health gains and impose financial and economic costs on households and governments. The prevalence of many NCDs and their risk factors have been on the rise over the years while the impact on personal and corporate finances can simply be imagined.

[25-27] in low and middle-income countries. As NCDs progress, financial implications rise as complex procedures such as multiple drugs, recurrent hospitalization, surgeries, device therapies in heart failure, pacemakers, haemodialysis, chemotherapy, long-term 
oxygen therapy become necessary and account for the enormous cost implication of these diseases. The high financial implications of NCDs among the study participants may be related to their chronic nature as most of them have been on treatment for years. The present study also revealed that NCDs are associated with significant psycho-social implications with direct and indirect impact on household and personal finances. Many of the subjects with NCDs in this study had a significantly higher frequency of hospital visits, were more likely to spend long hours in the hospital and were more likely to have a family member with prolonged illness than controls. All these will subsequently have a negative impact on corporate, household and personal finances. This observation is similar to other reports that have shown an association between NCDs and family history of diseases and the frequency of hospital visits with a substantial increase in economic burden on individuals and health institutions. [3,4,12,17] Therefore, initiation of population-oriented health education for primary and secondary prevention is a major step towards the reduction of the burden of NCDs in the whole population. [28-29]

Even though out-of-pocket expenses constitute the most common type of health financing among the subjects in the present study, a significant proportion of those with NCDs needed to depend on family supports to off-set medical expenditures with indirect impoverishing and increased economic strain on families and relatives of people with NCDs. This study also revealed that NCDs are common at the fifth and sixth decades of life similar to reports from other centres. $[1,4,10]$ These age groups are associated with limited financial resources as they are likely to have retired from active service. Efforts at reducing the economic burden of NCDs in the society should include the implementation of health insurance schemes for the populace, provision of incentives for local manufacturers of drugs to reduce cost, better hospital policies to reduce the man-hours spent during consultation and other health-seeking behaviours, subsidizing drugs for NCDs and financial empowerment of the population at risk. The latter should include a regular upward review of the benefits and allowances of retirees in order to enhance their ability to cater for the upsurge of NCDs in that age group.

This study also revealed that a considerably higher proportion of subjects with NCDs reported their health to be in a bad state or even worse in their own estimation. This selfassessment is an indicator of the relatively high impact of NCDs on affected subjects and this adversely impacted their self-esteem and quality of life. This study also revealed that a sizable group of subjects with NCDs spent more than 10,000 Naira per month on monthly routine expenses. In this nation, the minimum basic pay for workers is 18,000 Naira per month. This leaves a very serious negative impact on available finances for other basic needs of life such as accommodation and feeding. A significant proportion of sufferers of NCDs also had catastrophic health expenditure with regular health-related monthly expenses exceeding monthly expenses. In the absence of family supports and other corporate assistance, individuals with NCDs are at risk of early death from the diseases. Non-governmental organizations can also help to reduce the burden by providing health insurance for the less privileged, supplement health expenditure of the very poor and upgrade of hospital facilities. The various tiers of governments in Nigeria also need to increase their yearly budgetary allocation to health, improve the health system and revitalize the National Health Insurance Scheme for better coverage of the citizenry.

\section{Conclusion}

The management of non-communicable disease has significant psycho-social and economic impact on affected subjects in South- 
west Nigeria with a tendency to worsen poverty and affect the quality of life. Appropriate health insurance and health system financing programmes may reduce long-term complications in Nigeria and improve their quality of life.

Acknowledgements: The resident doctors in the Department of Medicine, LAUTECH Teaching Hospital, Ogbomoso, Nigeria are appreciated.

Authors' Contributions: ATS, AAA1 and AAA2 were involved in the conceptualization and design of the study. AAA1 participated in data analysis. All the authors participated in the drafting of the manuscript and approved the final version of the manuscript.

Conflict of Interest: None declared.

Funding: Self-funded.

Publication History: Submitted 23 June 2018; Revised 22 July 2018; Accepted 09 August 2018.

\section{References}

1. Kengne AP, June-Rose McHiza $Z$, Amoah AG, Mbanya JC. Cardiovascular diseases and diabetes as economic and developmental challenges in Africa. Prog Cardiovasc Dis 2013; 56(3): 302-13.

2. Health Reform Foundation of Nigeria (HERFON). Diabetes to top cause of death in 2015. Available at www.vanguardngr.com/2011/10/diabe tes-to-top-cause-of-death-in-2015healthgroup. Accessed 15th December 2017.

3. Remais JV, Zeng G, Li G, Tian L, Engelgau MM. Convergence of noncommunicable and infectious diseases in low- and middle-income countries. Int J Epidemiol 2013; 42(1): 221-7.

4. Ekpenyong CE, Udokang NE, Akpang EE, Samson TK. Double burden, noncommunicable diseases and risk factors evaluation in sub-Saharan Africa: The Nigerian Experience. Eur J Sustainable Dev 2012; 1(2): 249-70.
5. Miranda JJ, Kinra S, Casas JP, Davey Smith G, Ebrahim S. Non-communicable diseases in low- and middle-income countries: context, determinants and health policy. Trop Med Int Health 2008; 13(10): 1225-34.

6. Kankeu HT, Saksena P, Hu Ke, Evans DB. The financial burden from noncommunicable diseases in low and middle- income countries: a literature review. Health Res Policy Systems 2013; 11: 31. DOI: 10.1186/1478-4505-11-31.

7. McIntyre D, Thiede M, Dahlgren G, Whitehead M. What are the economic consequences for households of illness and of paying for health care in low- and middle-income country contexts? Soc Sci Med 2006; 62: 858-65.

8. Engelgau M, Rosenhouse S, El-Saharty $S$, Mahal A. The economic effect of noncommunicable diseases on households and nations: a review of existing evidence. J Health Comm 2011; 16: 7581.

9. Onoka CA, Hanson K, Hanefeld J. Towards universal coverage: a policy analysis of the development of the National Health Insurance Scheme in Nigeria. Health Policy Plan 2015; 30(9): 1105-17.

10. Robinson HM, Hort K. Noncommunicable diseases and health systems reform in low-and-middleincome countries. Pac Health Dialog 2012; 18(1): 179-90.

11. Bakare AS. Measuring the Income Inequality in Nigeria: the Lorenz Curve and Gini Co-efficient Approach. Am J Econ 2012; 2(1): 47-52.

12. Oni $\mathrm{T}$, Unwin $\mathrm{N}$. Why the communicable/non-communicable disease dichotomy is problematic for public health control strategies: 
implications of multimorbidity for health systems in an era of health transition. Int Health 2015; 7(6): 390-9.

13. Boutayeb A. The double burden of communicable and non-communicable diseases in developing countries. Trans R Soc Trop Med Hyg. 2006; 100(3): 191-9.

14. Amuna P, Zotor FB. Epidemiological and nutrition transition in developing countries: impact on human health and development. Proc Nutr Soc 2008; 67(1): 82-90.

15. John EU. The Impacts of User Fees on Health Services in Sub-Saharan African Countries: A Critical Analysis of the Evidence. Am J Pub Health Res 2013; 1(8): 196-202.

16. Abegunde D, Stanciole A. An estimation of the economic impact of chronic noncommunicable diseases in selected countries. A working paper. World Health Organization Department of Chronic Diseases and Health Promotion (CHP) http://www.who.int/chp. Accessed on the 18th December 2017.

17. Engelgau MM, Karan A, Mahal A. The Economic impact of Non-communicable Diseases on households in India. Global Health. 2012; 8: 9. doi.10.1186/17448603-8-9.

18. Temu F, Leonhardt M, Carter J, Thiam S. Integration of non-communicable diseases in health care: tackling the double burden of disease in African settings. Pan Afr Med J 2014; 18: 202.

19. Schofield D, Passey M, Percival R, Shrestha R, Callander E, Kelly S: Retiring early with cardiovascular disease - impact on individual's financial assets. Int J Cardiol 2010; 92: $125-6$.
20. Barrett AM, Colosia AD, Boye KS, Oyelowo O. Burden of Obesity: 10-year Review of the Literature on Costs in Nine Countries. Toronto, Canada: ISPOR 13th Annual International Meeting; 2008.

21. Langa KM, Fendrick AM, Chernew ME, Kabeto MU, Paisley KL, Hayman JA. Out-of-pocket health-care expenditures among older Americans with cancer. Value Health 2004; 7: 186-94.

22. Wang $Q$, Brenner $S$, Kalmus $\mathrm{O}$, Banda $\mathrm{HT}$, De Allegri M. The economic burden of chronic non-communicable diseases in rural Malawi: an observational study. BMC Health Serv Res 2016; 16: 457-60.

23. Jaspers L, Colpani V, Chaker L, van der Lee SJ, Muka T, Imo D, et al. The global impact of non-communicable diseases on households and impoverishments: a systematic review. Eur J Epidemiol 2015; 30(3): 163-88.

24. Maiyaki MB, Garbati MA. The burden of non-communicable diseases in Nigeria; in the context of globalization. Ann Afr Med 2014; 13(1): 1-10.

25. Janssens W, Goedecke J, de Bree GJ, Aderibigbe SA, Akande TM, Mesnard A. The financial burden of Noncommunicable diseases in rural Nigeria: Wealth and gender heterogeneity in health care utilization and health expenditure. PLoS One. 2016; 11(11): e0166121.

26. Muka T, Imo D, Jaspers L, Colpani V, Chaker L, van der Lee SJ, et al. The global impact of non-communicable diseases on healthcare spending and national income: a systematic review. Eur J Epidemiol. 2015; 30(4): 251-77.

27. World Health Organization. Global burden of disease report, Nigeria available 
http://www.healthdata.org/nigeria.

Accessed 22 ${ }^{\text {nd }}$ January 2018.

28. Mensah GA. Tackling noncommunicable diseases in Africa: Caveat Lector. Health Educ Behav 2016; 43(1): 7S-13S.

29. Amuyunzu-Nyamongo M, Owuor JO, Blanchard C. The consortium for NCD prevention and control in sub-Saharan Africa (CNCD-Africa): from concept to practice. Glob Health Promot. 2013; 20(4): 97-103. 